\title{
Enterprise Models as Data
}

\author{
Marite Kirikova, Ligita Businska, and Anita Finke \\ Riga Technical University \\ \{marite.kirikova,ligita.businska\}@cs.rtu.lv, anita.finke@rtu.lv
}

\begin{abstract}
In many cases enterprise models are considered as a part of enterprise knowledge. This paper examines the status of enterprise model as an artifact that is a part of organizational information system. In this view, the enterprise models are a part of information flow in the organization, and in their static state can be regarded as data rather than knowledge. This view helps to understand why the usability of enterprise models is still quite low in spite of the availability of powerful and sophisticated enterprise modeling tools and environments that allow to construct, analyze, maintain, configure, and integrate different types of models and even generate code and configure software subsystems on the bases of models amalgamated in the tools.
\end{abstract}

Keywords: data, information, knowledge, information system, enterprise model.

\section{Introduction}

Usually enterprise models (EM) are considered as a part of organizational knowledge [1]. Not denying this perspective of EM, in this paper, we analyze in more detail the nature of this artifact and we look at it from the point of organizational information system (IS) in a somewhat non-traditional way, namely, using the extended IS approach where the IS is considered not merely as a data flow that supports organizational operation and management, but also as a flow of data that supports organizational changes including the changes in IS itself. The EM is considered as an essential part of IS with multiple possible ways of use and development.

The research question addressed here is as follows: what is the role of EM in the organizational IS and when can EM be considered as knowledge, when as data, and when as information?

In order to answer the above mentioned question Section 2 starts with the analysis of notion of information. Section 3 examines three potential roles of EM in organizational IS. Section 4 presents a simplified organizational IS model that considers EM as data. Section 5 analyzes problems that arise in the use of EM as information in organizational processes. Section 6 consists of brief conclusions and points to further research directions.

\section{On the Notion of Information}

Information may be regarded as nonmaterial entity which allows describing real (material) and mental (nonmaterial) entities with any degree of precision $[2,3,4,5]$. This 
view about information differs to some extent from the well known interpretation of Shanoon's use of the term that suggests information as a successful selection of symbols or words from a given vocabulary [6] that pays less attention to the meaning of the information. According to [2] information has the following features:

- Information does not exist outside of interaction between objects

- Objects do not lose information during interaction

- Information is delivered with the purpose of satisfying some goals of the receiver

- Informational interaction may happen only if a particular fit exists between the provider and receiver of information.

This means that information is a phenomenon that exists at the momentum of interpretation of data by a particular knowledge system. The interpretation may be done by natural knowledge system (human knowledge) or, if we use software as a part of IS, the interpretation may be done by artificial knowledge system, i.e., human knowledge coded in a particular software system [7]. Thus, it is essential that EMs that are produced by a particular group of people are meaningfully perceivable by human and artificial knowledge operating in the enterprise. On the other hand, it is essential to distinguish between two different types of information availability. First, information may be available without the purpose of information provision. Second, information may be provided purposely by "pushing" it to the intended receiver or making it available for some known or unknown "poolers" [8]. Sticking to the point that information is (1) interpreted data [8] and (2) exists only at the momentum of interaction between at least two natural or artificial objects, we can conclude that there are two phenomena that are essential for existence of information, namely data which is interpreted and knowledge that interprets the data. Furthermore, taking into consideration the dynamic nature of knowledge (knowledge changes in each moment of data interpretation) $[1,8,9]$, we can conclude that the only static tangible phenomenon, changes of which can be relatively easily traced, is data. In the next section we analyze three different roles of EM in organization, namely, data, information, and knowledge.

\section{Three Roles of EM}

In order to view EM in three different roles (data, information, and knowledge) it is necessary to examine the nature of EM and the process of its creation. Usually the EM is created on the basis of already existing tacit and explicit knowledge [1, 10]. In general, in order to locate knowledge sources it is important to distinguish between master's knowledge and observer's knowledge concerning the object of interest (Figure 1). Both, master and observer have tacit knowledge and can provide explicit knowledge.

However, there can be quite considerable difference not only regarding the tacit but also explicit knowledge provided by the master of the object in comparison to the knowledge provided by the observer of the object. Thus, the agent (in case of EM creation - the enterprise modeling group) that seeks knowledge about a particular object has the following main sources of knowledge (Figure 1): 


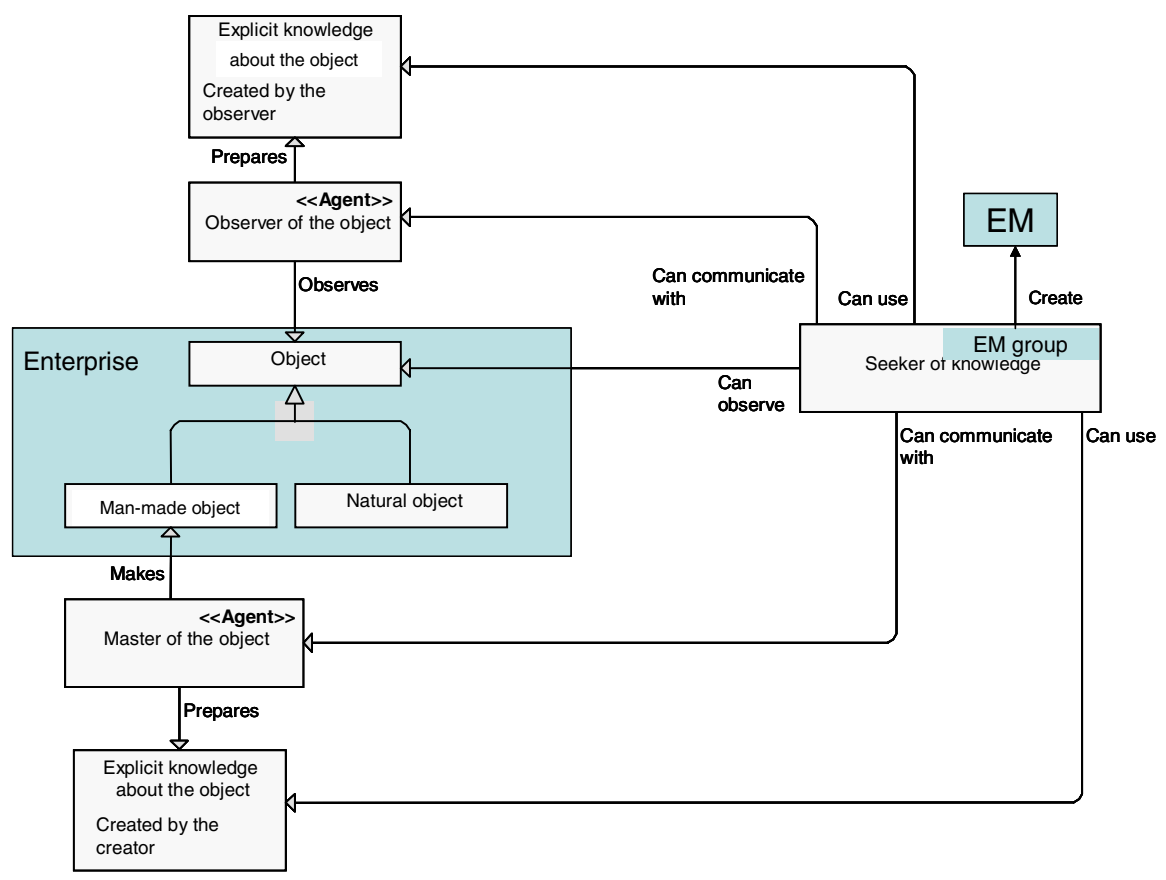

Fig. 1. Knowledge sources of EM

- The object of interest that represents knowledge, i.e., an enterprise consisting of natural and man-made objects.

- The agents that have made man-made objects (masters of the object), e.g., employees and managers of the enterprise

- The agents that have observed (or investigated) the object (observers of the object), such as business analysts, systems analysts, consultants and to some extent IS staff in general.

- Explicit knowledge that has been prepared by the masters of the object (externalized master's knowledge)

- Explicit knowledge that has been prepared by the observers of the object (externalized observer's knowledge)

- Seeker of knowledge, e.g., EM development group whose purpose is to create an EM

Actually, EMs developed at different times may be represented as man-made objects, explicit knowledge about the object and as a result of work of EM group. In Figure 1 active possessors of knowledge are divided in three classes, namely - master of the object, observer of the object, and seeker of knowledge. In EM development one and the same person and one and the same group of persons may belong to several classes of knowledge possessors. The master of the object is an agent who has made the object, the observer of the object is an agent who has investigated the object by methods available at its disposal. The knowledge seeker is an agent whose goal is to obtain 
knowledge about the object. Human agents can obtain knowledge even without a conscious aim of knowledge acquisition [9]. In Figure 1 the situation of purposeful knowledge acquisition is reflected. There is a difference in quality, richness and completeness between the knowledge of the master of the object and the knowledge of the observer of the object. Actually, as experience shows, the observer must learn to make himself or herself an object to obtain knowledge that is adequate with the master's knowledge (see the example about the development of bread making machine in [11]).

Figure 1 reflects knowledge sources from the point of view of the knowledge seeker at a particular point of time $\mathrm{t}_{\mathrm{i}}$. However, two other agents can be also considered as seekers of knowledge. Actually, the observer of the object would not be used as a source of knowledge if it had not been a seeker of knowledge at some point of time $t_{j}=t_{i}-\Delta t, \Delta t \geq 0$. None of the agents depicted in Figure 1 can possess complete knowledge about natural objects; therefore, the master of the object becomes a seeker of knowledge when it observes a natural object or the object that includes natural objects. On the other hand, the seeker of knowledge likewise can take the roles of the observer and the master [12].

In view of the abovementioned complexity of knowledge development during enterprise modeling, EM at its particular development sate at a particular point of time $\mathrm{t}_{\mathrm{j}}$ may be regarded as data (hard or soft depending on the means of representation) looking from the point of independent observer: it may be regarded as an amalgamation of pieces of knowledge of individuals participating in enterprise modeling activities; and it may be considered as information at moments when EM is processed by the brain of its human users or by particular software tools. Thus, in order to become useful information in IS development, EM and natural or/and artificial knowledge supposed to use it are to fit one another (see section 2). In case of non-fit EM may become useless. A simplified model of the role of EM in enterprise IS is provided in the next section. It will allow to look closer at the issues of fit between EM and the knowledge that can interpret it.

\section{A Simplified Model of Use of EM}

There are several reasons why EMs are used in organizations [13]. In this paper we consider two purposes of EM use, first, managing an enterprise and, second, developing and maintaining the enterprise IS (Fig. 2). The situation is quite straightforward and to some extent controllable at the first go of EM creation. In this situation those involved in EM development become its users for organizational management and IS development purposes. A new situation arises when new versions of EM are developed. Due to the dynamic nature of knowledge, all human knowledge that has been involved in EM development has changed and software has changed due to its maintenance. Consequently, the fit between the previous EM and actual knowledge that processes it may not be present. When a new EM is developed, the fit between the previous version of EM and the new one could be established using sophisticated modeling tools and human effort. However, the question is whether this fit makes any sense in terms of both enterprise management and IS development. It would make sense if at any moment of time the "vertical" fit between natural and artificial knowledge involved in enterprise management and data processing had been maintained. 
However, in practice it would mean continuous extra effort and continuous information overload to all human knowledge possessors in the enterprise. Theoretically it is achievable that every single change relevant to IS development and maintenance is reflected in the EM [7]. However up to this time nobody has actually examined how much effort and time it would require. In practice, in many cases, new EM are built from scratch again and again when new IS are to be developed or organizational problems resolved [14].

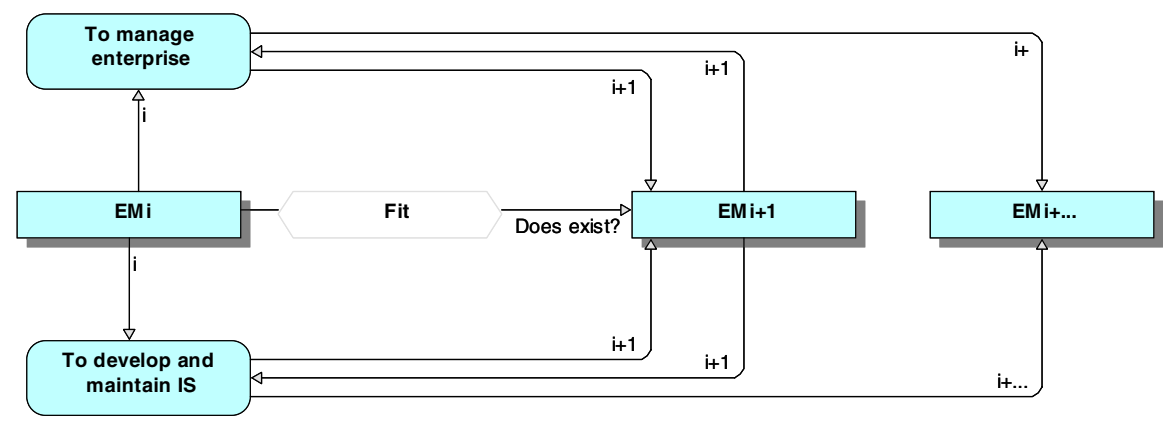

Fig. 2. Use of EM

According to Steven Alter [15] "an IS is a work system whose processes and activities are devoted to processing information, that is, capturing, transmitting, storing, retrieving, manipulating, and displaying information. A work system is a system in which human participants and/or machines perform work (processes and activities) using information, technology and other resources to produce specific products and/or services for specific internal or external customers". According to this definition an EM is a product of enterprise IS. Thus, the main question to be answered is who (what) are the customers of EMs and what specific value EMs can bring to their customers at specific time points of enterprise life cycle. Here we focus only on one essential requirement for EM to be valuable, namely, the EM should enable information circulation in organization, i.e., it should be interpretable by human and artificial knowledge of the enterprise. In the next section we consider some problems that currently hinder enterprise IS from obtaining value from enterprise modeling efforts.

\section{Difficulties in Obtaining Information from EM}

One of the essential aspects of EMs is that their construction is a time and effort demanding process. This, to some extent, is in contradiction with the need for frequent changes perceived in current historical situation of global economic development. For enterprise to be changeable, its IS also has to be changeable, and, in turn, the EM as a part of IS has to follow these changes. It means that data provided by EM has to change rapidly and the ability to interpret this data by humans or software also has to change rapidly. According to [16], changeability involves four essential features namely, agility, adaptability, robustness, and flexibility. 
Agility usually is related to speed. The more rapidly the system will operate, the quicker the users will react to changes; that will lead to the user satisfaction. Still, the agility of the system is not reflected only in the speed of operations. It is reflected also in the time needed to complete any of the intended operations. If the system is designed in a way that allows the user to perform a certain action as simply as possible, the amount of time spent is small; therefore we can define that action as one that is relatively easy to carry out. Thus to achieve the agility needed for changeability the development and use of EM should be perceived as a simple activity by the "customers" of the EM [17]. This differs from the current practice of enterprise modeling.

Nowadays systems are designed to adapt to the users and the intensity of operations. We should note that all users are not the same and everyone has professional and personal peculiarities when it comes to the use of systems. Adaptability can be referred to moments when the system is adapted or adapts to work in a certain way at definite moments and with definite users. IS that includes EM has to successfully trace the moments when it can save some of the resources (e.g., time of EM developers or users), or vice versa - use all the available resources. Adaptability of EM has not been researched properly and may imply the use of artificial intelligence techniques in EM building and maintenance.

The environment that surrounds us is stochastic (changing). There is a continuous introduction of new technologies, new needs and changing market conditions, etc. It is important for the system to be robust, i.e., to be stable and to be able to last apart from a certain range of changes. How to achieve robustness of enterprise models is still an open question. Probably it is necessary to distinguish between stable and frequently changeable parts of EMs.

Changing the system each time a new product appears is unfavorable. In systems with high level of flexibility options should be introduced that allow the user without any specific preliminary knowledge to quickly add additional parameters that previously have not been listed in the system. Some improvements here are related to active knowledge modeling [1]. Nevertheless flexibility in current developments does not always go hand in hand with simplicity if we consider the use of EM as a whole not just role-oriented parameterization of particular parts of the EM.

Changeability includes all the previously mentioned factors. In view of the problems in EM in connection with these factors we can conclude that there is still a long way to go before we achieve genuine development and use of EM in practice.

\section{Conclusions}

This paper examined the role of EM in enterprise IS focusing on its use as mere data rather than knowledge. This approach helped to reveal and partially structure basic problems of EM development and use, such as lack of agility, non-investigated adaptability, vague requirements for robustness, and fragmentary flexibility. These problems highlight the following directions in EM usability research: (1) How to balance simplicity and complexity in EM development and use; (2) What are the possibilities of the use of artificial intelligence in EM development and maintenance; (3) How to achieve robustness of EM without losing flexibility. 
Those research directions show that while EMs usually are considered in the context of organizational knowledge management, it is still necessary to be aware of the fact that without the possibility to be interpreted EMs are nothing more than data; and in many cases may become just useless data to be discarded from organizational memory despite of availability of powerful and sophisticated enterprise modeling tools and environments that allow to construct, analyze, maintain, configure, and integrate different types of models and even generate code and configure software subsystems on the basis of models amalgamated in the tools.

\section{Acknowledgment}

The research work reflected in this paper is partly sponsored by Latvian Council of Science, Grant No. 09.1245.

\section{References}

1. Lillehagen, F., Kroghstie, J.: Active Knowledge Modeling of Enterprises. Springer, Heidelberg (2008)

2. Jankowski St.: A concept of general theory of information (Станислав Янковски Концепции общей теории информации), http://n-t.ru/tp/ng/oti.htm

3. Moon, T.: Information Theory, Electrical and Computer Engineering, Utah State University, http: / /ocw.usu.edu/Electrical_and_Computer_Engineering/ Information_Theory

4. Carter, T.: An introduction to information theory and entropy (2007), http: //astarte.csustan.edu/ tom/SFI-CSSS/info-theory/ info-lec.pdf

5. Corning, P.A.: Control Information Theory: The 'Missing Link' in the Science of Cybernetics. System Reseach and Behavioral Science, Syst. Res., 297-311 (2007)

6. Shannon, C.E.: A Mathematical Theory of Communication. Reprinted with corrections from The Bell System Technical Journal 27, 379-423, 623-656 (1948)

7. Kirkova, M., Grundspenkis, J.: Using knowledge distribution in Requirements Engineering. In: Leondes, C.T. (ed.) Knowledge-Based Systems, Four-Volume Set: Techniques and Applications. Academic Press International, London (2000)

8. Tiwana, A.: The knowledge management toolkit: Orchestrating IT, Strategy, and Knowledge Platforms, 2nd edn. Prentice-Hall, Englewood Cliffs (2002)

9. Anderson, J.R.: Cognitive Psychology and its Implications, 4th edn. W.H. Freeman and Company, New York (1995)

10. Bubenko Jr., J.A., Persson, A., Stirna, J.: User Guide of the Knowledge Management Approach Using Enterprise Knowledge Patterns, deliverable D3, IST Programme project Hypermedia and Pattern Based Knowledge Management for Smart Organisations, project no. IST-2000-28401, Dept. of Computer and Systems Sciences, Royal Institute of Technology, Stockholm, Sweden (2001), http://www.dsv.su.se/ js/ekd_user_guide.html

11. Nonaka, I., Takeuchi, H.: The Knowledge Creating Company: How Japanese Companies Create the Dynamics of Innovation. Oxford University Press, New York (1995)

12. Kirikova, M., Grundspenkis, J.: Types of knowledge and knowledge sources. In: Scientific Proceedings of Riga Technical University, Series Computer Science: Applied Computer Systems, RTU, Riga, pp. 109-119 (2002) 
13. Persson, A., Stirna, J.: An explorative study into the influence of business goals on the practical use of Enterprise Modelling methods and tools. In: Harindranath, G., et al. (eds.) New Perspectives on Information Systems Development: Theory, Methods and Practice, pp. 215-288. Kluwer Academic, New York (2002)

14. Ambler, S.: Introduction To Agile Modeling, white paper. Ronin International (2002)

15. Alter, S.: Defining information systems as work systems: implications for the IS field. European Journal of Information Systems 17, 448-469 (2008)

16. Fricke, E., Shulcz, A.P.: Design for changeability (DfC): Principles to enable changes in systems throughout their entire lifecycle. Systems Engineering 8, 342-359 (2005)

17. Maeda, J.: The laws of simplicity. The MIT Press, Cambridge (2006) 